Research Paper

\title{
Increased Levels of Serum Protein Complexes Are Associated with Type 2 Diabetes
}

\author{
Yujie Liu${ }^{1}$, Yunpeng $\mathrm{Wu}^{1}$, Yanmin Wang ${ }^{2}$, Mo Zhang1, and Zhili Li ${ }^{1 凶}$ \\ 1. Department of Biophysics and Structural Biology, Institute of Basic Medical Sciences, Chinese Academy of Medical Sciences \& School of Basic Medicine, \\ Peking Union Medical College, Beijing 100005, PR China \\ 2. Department of Clinical Laboratory, Heze Municipal Hospital, Shandong 274031, PR China \\ $\triangle$ Corresponding author: Zhili Li, Department of Biophysics and Structural Biology, Institute of Basic Medical Sciences, Chinese Academy of Medical Sciences \\ \& School of Basic Medicine, Peking Union Medical College, 5 Dongdan San Tiao, Beijing 100005, PR China. Tel/Fax: +86 10 69156479; E-mail: \\ lizhili@ibms.pumc.edu.cn \\ (C) Ivyspring International Publisher. This is an open access article distributed under the terms of the Creative Commons Attribution (CC BY-NC) license \\ (https://creativecommons.org/licenses/by-nc/4.0/). See http://ivyspring.com/terms for full terms and conditions.
}

Received: 2017.08.24; Accepted: 2017.11.23; Published: 2018.01.01

\begin{abstract}
Objective: To screen novel biomarkers in the levels of protein complexes for type 2 diabetes mellitus (T2DM).

Methods: Serum immunoinflammation-related protein complexes (IIRPCs) and diabetes-related protein complexes (DRPCs) in 1537 serum samples including 504 healthy controls, 320 patients with prediabetes, and 713 patients with T2DM were analyzed using an optimized native polyacrylamide gel electrophoresis (native-PAGE).

Results: Seven patterns of serum IIRPCs and four patterns of serum DRPCs were observed in the study population, respectively. Significant increase in the levels of serum IIRPCs in T2DM was detected relative to healthy controls. Change trends of serum DRPCs are as below: patients with T2DM>ppatients with prediabetes> healthy controls.

Conclusion: Our findings suggest that increased levels of serum IIRPCs and DRPCs were associated with T2DM.
\end{abstract}

Key words: protein complex; diabetes-related protein complex; type 2 diabetes

\section{Introduction}

Diabetes mellitus, especially for type 2 diabetes mellitus(T2DM), is a chronic, incurable disease, and the efforts of a number of investigators have been made to probe pathogenetic mechanisms and therapy of T2DM [1]. Major factors, such as obesity, pancreas $\beta$-cell dysfunction, mitochondrial dysfunction, and oxidative stress, are closely associated with T2DM [2]. It is found that low-grade inflammation and the activation of innate immune system are closely related to the pathogenesis of T2DM[3-5].The levels of circulating inflammatory markers, such as $C$ reactive protein(CRP), a-1 acid glycoprotein, amyloid A, IL-6, and IL-1Ra, significantly elevated in patients with T2DM[6-8].

Previous studies have shown that protein complexes are potential indicators of many diseases. Trypsin 2- $\alpha_{1}$ antitrypsin complex displayed a better diagnostic performance than trypsinogen 2 and CRP in differentiating acute pancreatitis from extrapancreatic disease [9], and myeloid-related protein 8/14 complex is a sensitive indicator of disease activity [10]. Circulating immunoinflammation-related protein complexes (IIRPCs) are closely associated with chronic diseases [11]. To date, the correlations between serum IIRPCs and T2DM have not been investigated.

Quantification of known protein complexes is usually performed using radioimmunoassy, immunofluorescence assay, or enzyme-linked immunosorbent assay [12-14]. Blue native gel and high resolution clear native gel are powerful approaches to isolate protein complexes $[15,16]$. Herein, an optimized native polyacrylamide gel electrophoresis (native-PAGE) was employed to 
isolate protein complexes of interest in 1537 serum samples. Based on the position distributions of the gel bands of the protein complexes of interest in gel, two types of serum protein complexes are observed in this study, i.e., IIRPCs $[11,17]$ and diabetes-related protein complexes (DRPCs).

\section{Materials and Methods}

\section{Participants}

In this study, 1537 participants were recruited from the medical examination center, Heze Municipal Hospital (Shandong, China). These participants were classified into three groups (i.e., healthy controls, patients with prediabetes, and patients with T2DM) based on the levels of the overnight fasting plasma glucose (FPG) as described by the criteria of the American Diabetes Association[18]. Informed consent was obtained from each participant. Serum was collected according to a previously described standard procedure [11]. This study was approved by the Ethics Review Committee at the Institute of Basic Medical Sciences, Chinese Academy of Medical Sciences within which the work was undertaken and that it conforms to the provisions of the Declaration of Helsinki.

\section{Native-PAGE separation}

The protein complexes of interest were isolated using our own previous procedure with slight modifications [11, 19]. Briefly, 4\%-10\% linear gradient acrylamide gel and $4 \%$ acrylamide gel were used as separating gel and stacking gel, respectively. $2 \mu \mathrm{L}$ of serum sample mixed with $8 \mu \mathrm{L} 1 \times$ native loading buffer $(25 \%$ v/v $50 \mathrm{mM}$ Tris- $\mathrm{HCl} \mathrm{pH} 7.5 ; 50 \%$ v/v glycerol; $0.1 \% \mathrm{w} / \mathrm{v}$ XYlenecyanol FF) was loaded into one lane of gel. Each gel was run at $10 \mathrm{~mA}$ for $1.5 \mathrm{~h}$, followed by $25 \mathrm{~mA}$ for $3 \mathrm{~h}$. The gels were stained with Coomassie brilliant blue G-250, and then the background was destained in deionized water. Optical image was obtained using an UMAX PowerLook 2100XL scanner (UMAX Technologies, Dallas, TX, USA) for optical densitometry-based quantification, and then the optical densitometry (i.e., gray value) was quantified using Quantity One software (version 4.6.3, Bio-Rad).

\section{Quantification of serum protein complexes of interest}

Nine serum samples and one quality control (QC) serum sample were loaded into ten lanes of one native-PAGE gel, respectively. The QC sample was a mixture of three control sera. The gel image was introduced into Quantity One software, and the levels of serum protein complexes of interest were calculated using the following formula: the level of protein complex $=$ gray value of gel band - gray value of gel background. The level of serum transferrin-related protein complex (TRPC) in each serum sample was quantified relative to that of the QC sample. The levels of serum protein complexes of interest were quantified relative to that of serum TRPC which is normalized to 100[11]. To evaluate the reproducibility of this method, four serum samples (i.e., the QC sample, one control, one patient with prediabetes, and one patient with T2DM) were used to examine intraday and interday precision of the method.

\section{Identification of serum protein complexes of interest}

Each gel band in native-PAGE gel was transferred into a $0.6 \mathrm{~mL}$ eppendorf tube, followed by the incubation for $45 \mathrm{~min}$ at room temperature in the equilibrium buffer (93.8 mM Tris- $\mathrm{HCl}, \mathrm{pH} 6.8,10 \%$ $\mathrm{v} / \mathrm{v}$ glycerol, $2 \% \mathrm{w} / \mathrm{v}$ sodium dodecyl sulfate) including $3 \%(\mathrm{w} / \mathrm{v})$ dithiothreitol, and then the band was incubated for $35 \mathrm{~min}$ at room temperature in the above-mentioned equilibrium buffer with $10 \%(\mathrm{w} / \mathrm{v})$ iodoracetamide. The gel band was further separated using sodium dodecyl sulfate-PAGE. Each gel was run at $60 \mathrm{~V}$ for $1 \mathrm{~h}$, followed by $120 \mathrm{~V}$ for $2 \mathrm{~h}$. Gel bands from the sodium dodecyl sulfate-PAGE gel were excised and digested followed by the identification of the proteins of interest as described previously [11].

\section{Statistical analysis}

Normal distribution of variables was evaluated by Shapiro-Wilk test, and categorical variables were analyzed using Pearson $\chi^{2}$ test. Student's $t$ test or Mann-Whitney $U$ test was used to compare the differences between two groups. The variables of subjects were compared among three groups using Kruskal-Wallis test. Receiver operating characteristic (ROC) curve analysis was performed to evaluate diagnostic performance. Statistical analysis was performed using the SAS software (version 9.2, SAS Institute Inc., Cary, NC, USA). A p-value less than 0.05 was considered to be statistically significant based on two-tailed tests.

\section{Results}

\section{Linear dynamic range and reproducibility}

To explore an appropriate loading volume of serum sample, different volumes of serum from 0.2 $\mu \mathrm{L}$ to $3 \mu \mathrm{L}$ were loaded into different lanes in one native-PAGE gel to evaluate linear dynamic range. Finally, linear correlation coefficient $\left(\mathrm{R}^{2}=0.977\right)$ was found over the range of $0.2 \mu \mathrm{L}$ to $2.5 \mu \mathrm{L}$, and for thyroglobulin (Sigma-Aldrich, St, Louis, MO), linear 
correlation coefficient $\left(\mathrm{R}^{2}=0.981\right)$ was detected over the range of $0.1 \mu \mathrm{g}$ to $2.5 \mu \mathrm{g}$. The reproducibility of the method was also assessed based on the four serum samples, with relative standard deviations (RSDs) of intraday precision from $4.3 \%$ to $17.5 \%$ and of interday precision from $5.0 \%$ to $19.3 \%$ for serum protein complexes: TRPC, a3, b4, T1, and T2 (Figure 1).

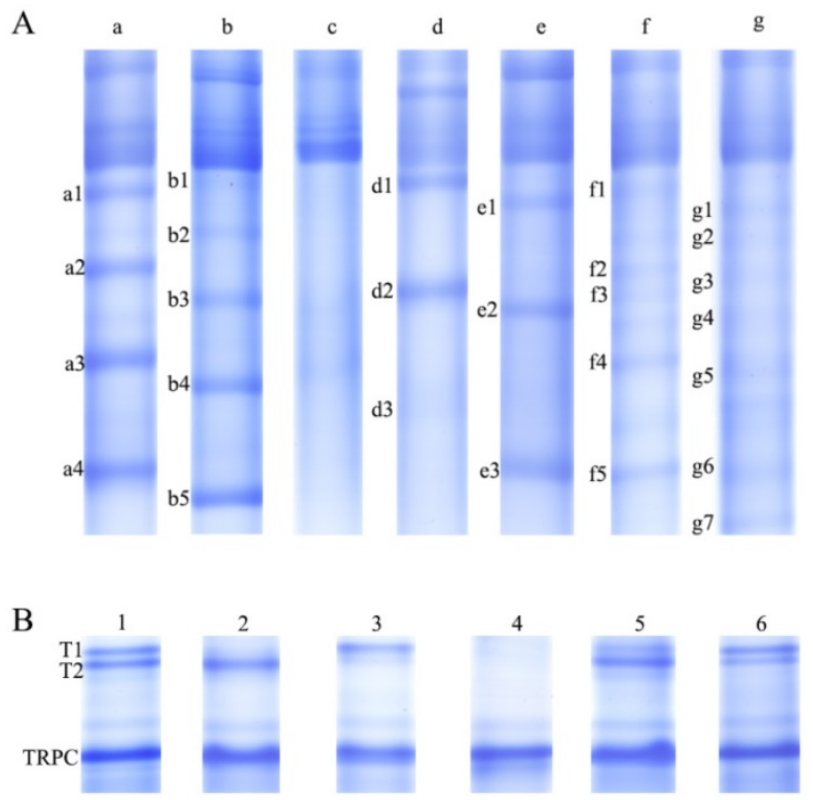

Figure 1. Serum protein complex separation by the optimized native-PAGE gel. (A) Seven patterns (i.e., a, b, c, d, e, f, and g) of serum immunoinflammation-related protein complexes (IIRPCs). (B) Six patterns (i.e., $1,2,3,4,5$, and 6) of serum diabetes-related protein complexes (DRPCs).

\section{Quantification of serum TRPC}

Ninety one serum samples (i.e., 20 healthy controls, 20 patients with prediabetes, and 51 patients with T2DM) were excluded due to the aberrant expression of serum TRPC. Finally, 1446 serum samples were used for further analysis, including 484 controls, 300 patients with prediabetes, and 662 patients with T2DM (Table 1). To investigate whether serum TRPC is an internal reference to quantify serum protein complexes of interest, the relationships between its level and several other variables (i.e., sex, age, patterns, and health status) were analyzed. Statistical analysis indicated that the level of serum TRPC in 1446 serum samples has no statistical significance $(p>0.05$, Table 2$)$, indicating that serum TRPC could be used as an internal reference to quantify serum protein complexes of interest.

\section{Association of serum IIRPCs with pathological status}

Seven major patterns ( $a, b, c, d, e, f$, and g) of serum IIRPCs in 1446 serum samples were observed based on their native-PAGE gels (Figure 1A), which is consistent with our previous study [11]. Each of these patterns accounts for approximately $34 \%(n=498), 32 \%$ $(n=456), 17 \% \quad(n=244), 8 \% \quad(n=110), 2 \% \quad(n=36), 5 \%$ $(\mathrm{n}=71)$, and $2 \%(\mathrm{n}=31)$, respectively (Figure 1A). For pattern a, we assigned four specific IIPRCs (a1, a2, a3, and a4); for pattern $b$, five specific IIRPCs (b1, b2, b3, b4, and b5); for pattern c, no specific IIRPCs; for pattern $\mathrm{d}$, three specific IIRPCs $(\mathrm{d} 1, \mathrm{~d} 2$, and $\mathrm{d} 3$ ); for pattern e, three specific IIRPCs (e1, e2, and e3); for pattern $\mathrm{f}$, five specific IIRPCs (f1, $\mathrm{f} 2, \mathrm{f3}, \mathrm{f4}$, and $\mathrm{f} 5$ ); for pattern g, seven specific IIRPCs (g1, g2, g3, g4, g5, g6, and g7). Due to limited sample sizes of patterns d, e, $f$, and $g$, as well as pattern c without specific IIRPCs, we only selected patterns a and $b$ for further analysis in this study. Representative protein complex a3 in pattern $\mathrm{a}$ and $\mathrm{b} 4$ in pattern $\mathrm{b}$ were selected to investigate the relationships between their levels and pathological status (Table 3). Statistical analysis indicated that the levels of $\mathrm{a} 3$ and $\mathrm{b} 4$ in T2DM patients significantly increased compared with the corresponding controls $(p<0.05)$. However, no difference was detected between patients with prediabetes and controls (Figure 2A \&2B). In addition, the components of serum IIRPCs were separated by SDS-PAGE, followed by the identification using mass spectrometry, and they are immunoglobulin G1, immunoglobulin A1, haptoglobin, complement $\mathrm{C} 3$, complement $\mathrm{C} 4 \mathrm{~A}$, complement C5, complement C7, complement factor $\mathrm{H}$, transferrin, and apolipoprotein A-I, which is consistent with our previous study[11].

Table 1. Characteristics of the participants in this study

\begin{tabular}{llll}
\hline & Controls & Prediabetes & T2DM \\
\hline Characteristics & $\mathrm{n}=484$ & $\mathrm{n}=300$ & $\mathrm{n}=662$ \\
\hline Sex(M/F) & $227 / 257$ & $172 / 128$ & $326 / 336$ \\
Age(years) & $46.6 \pm 16.4$ & $50.9 \pm 13.9$ & $53.4 \pm 12.7$ \\
Glucose(mmol/L) & $4.9 \pm 0.4$ & $6.4 \pm 0.4$ & $9.8 \pm 3.1$ \\
Patterns of serum DRPCs & & & \\
1 & 193 & 102 & 214 \\
2 & 53 & 64 & 181 \\
3 & 218 & 127 & 250 \\
4 & 20 & 7 & 17
\end{tabular}

Data are described as mean \pm SD (standard deviation) or numbers.

\section{Association of serum DRPCs with pathological status}

Six major patterns $(1,2,3,4,5$, and 6$)$ of serum DRPCs in 1446 serum samples were detected based on their native-PAGE gels (Figure 1B). For patterns 1, 2, 3,5 , and 6 , two gel bands corresponding to serum protein complexes (T1 and T2) were clearly observed with slight differences in their gray values, while for pattern 4 both T1 and T2 were not detected. In order to simplify statistical analysis, we redefined these 
patterns based on the ratio of $\mathrm{T} 2$ to $\mathrm{T} 1$ (T2/T1). According to the following ratio values: $0.5<\mathrm{T} 2 / \mathrm{T} 1<$ 2 , $\mathrm{T} 2 / \mathrm{T} 1 \geqq 2$, and $\mathrm{T} 2 / \mathrm{T} 1 \leqq 0.5$, the patterns of serum DRPCs were reclassified into patterns 1,2 , and 3 .
Finally, the six patterns were reclassified into patterns1, 2, 3, and 4 (Figure 1B and Table 1). The detailed information on the age- and sex-matched participants is listed in Table 4.

Table 2. Association of serum TRPC level with health status, sex, age, and patterns of serum DRPCs

\begin{tabular}{|c|c|c|c|c|c|c|}
\hline \multirow[b]{2}{*}{ Characteristics } & \multicolumn{2}{|c|}{ Controls $(n=484)$} & \multicolumn{2}{|c|}{ Prediabetes $(n=300)$} & \multicolumn{2}{|c|}{ T2DM $(n=662)$} \\
\hline & Level & $p$ value & Level & $P$ value & Level & $P$ value \\
\hline Health status & $1.02 \pm 0.07$ & & $1.01 \pm 0.07$ & 0.608 & $1.01 \pm 0.07$ & 0.362 \\
\hline \multicolumn{7}{|l|}{ Sex } \\
\hline Female & $1.02 \pm 0.07$ & 0.992 & $1.01 \pm 0.07$ & 0.771 & $1.01 \pm 0.07$ & 0.133 \\
\hline Male & $1.02 \pm 0.07$ & & $1.02 \pm 0.07$ & & $1.01 \pm 0.07$ & \\
\hline \multicolumn{7}{|l|}{ Age(years) } \\
\hline$<60$ & $1.02 \pm 0.07$ & 0.280 & $1.01 \pm 0.06$ & 0.143 & $1.01 \pm 0.07$ & 0.495 \\
\hline$>=60$ & $1.02 \pm 0.07$ & & $1.02 \pm 0.07$ & & $1.02 \pm 0.07$ & \\
\hline \multicolumn{7}{|c|}{ Patterns of serum DRPCs } \\
\hline 1 & $1.02 \pm 0.08$ & 0.571 & $1.00 \pm 0.05$ & 0.861 & $1.05 \pm 0.10$ & 0.131 \\
\hline 2 & $1.04 \pm 0.08$ & & $1.02 \pm 0.05$ & & $0.01 \pm 0.06$ & \\
\hline 3 & $1.02 \pm 0.07$ & & $1.01 \pm 0.07$ & & $1.01 \pm 0.07$ & \\
\hline 4 & $1.02 \pm 0.07$ & & $1.02 \pm 0.07$ & & $1.03 \pm 0.08$ & \\
\hline
\end{tabular}

Table 3. Characteristics of the age- and sex-matched participants in patterns a and b of serum IIRPCs

\begin{tabular}{|c|c|c|c|c|c|c|c|c|c|c|}
\hline & \multicolumn{5}{|c|}{ Pattern a } & \multicolumn{5}{|c|}{ Pattern b } \\
\hline & Controls & Prediabetes & $p$ value & T2DM & $P$ value & Controls & Prediabetes & $p$ value & T2DM & $p$ value \\
\hline Characteristics & $\mathrm{n}=148$ & $\mathrm{n}=108$ & & $\mathrm{n}=185$ & & $\mathrm{n}=131$ & $\mathrm{n}=97$ & & $\mathrm{n}=173$ & \\
\hline $\operatorname{Sex}(M / F)$ & $75 / 73$ & $64 / 44$ & & $93 / 92$ & 0.212 & $58 / 73$ & $45 / 52$ & & $80 / 93$ & 0.574 \\
\hline Age(years) & $49.7 \pm 15.9$ & $50.7 \pm 14.3$ & & $51.5 \pm 12.8$ & 0.338 & $49.6 \pm 14.8$ & $51.0 \pm 15.1$ & & $52.0 \pm 12.7$ & 0.266 \\
\hline Glucose(mmol/L) & $4.9 \pm 0.5$ & $6.4 \pm 0.4$ & & $9.8 \pm 2.9$ & & $4.9 \pm 0.5$ & $6.4 \pm 0.4$ & & $9.8 \pm 3.4$ & \\
\hline a3 & $20.8 \pm 13.1$ & $23.3 \pm 13.3$ & 0.102 & $26.0 \pm 16.8$ & 0.004 & ND & ND & & ND & \\
\hline b4 & ND & ND & & ND & & $17.2 \pm 11.3$ & $21.3 \pm 17.3$ & 0.090 & $21.7 \pm 14.5$ & 0.013 \\
\hline
\end{tabular}

Data are described as mean \pm SD or numbers.

I Pearson $\chi^{2}$ test for sex and Kruskal-Wallis test for age and Mann-Whitney U test for serum protein complexes a3 and b4 of prediabetes and diabetes and controls. All statistical tests are two-sided.

ND, no data.

Table 4. Characteristics of the age- and sex-matched participants in patterns 1,2 , and 3 of serum DRPCs

\begin{tabular}{|c|c|c|c|c|c|c|c|c|c|c|c|c|}
\hline & \multicolumn{4}{|c|}{ Pattern 1} & \multicolumn{4}{|c|}{ Pattern 2} & \multicolumn{4}{|c|}{ Pattern 3} \\
\hline & Controls & Prediabetes & T2DM & $P$ value & Controls & Prediabetes & T2DM & $p$ value & Controls & Prediabetes & T2DM & $P$ value \\
\hline Characteristics & $\mathrm{n}=180$ & $\mathrm{n}=102$ & $\mathrm{n}=185$ & & $\mathrm{n}=50$ & $\mathrm{n}=59$ & $\mathrm{n}=181$ & & $\mathrm{n}=165$ & $\mathrm{n}=127$ & $\mathrm{n}=210$ & \\
\hline $\operatorname{Sex}(\mathrm{M} / \mathrm{F})$ & $92 / 88$ & $55 / 47$ & $92 / 93$ & 0.744 & $20 / 30$ & $34 / 25$ & $86 / 95$ & 0.517 & $78 / 87$ & $72 / 55$ & $105 / 105$ & 0.268 \\
\hline Age(years) & $51.2 \pm 15.3$ & $51.5 \pm 14.1$ & $53.9 \pm 13.4$ & 0.082 & $53.1 \pm 16.6$ & $54.6 \pm 11.4$ & $53.7 \pm 10.5$ & 0.961 & $47.3 \pm 15.3$ & $47.7 \pm 14.3$ & $48.9 \pm 13.4$ & 0.313 \\
\hline Glucose $(\mathrm{mmol} / \mathrm{L})$ & $4.9 \pm 0.4$ & $6.4 \pm 0.4$ & $9.8 \pm 3.0$ & & $5.0 \pm 0.4$ & $6.6 \pm 0.2$ & $10.0 \pm 3.0$ & & $4.9 \pm 0.4$ & $6.3 \pm 0.4$ & $9.9 \pm 3.5$ & \\
\hline $\mathrm{T} 1$ & $11.7 \pm 7.6$ & $18.0 \pm 9.6$ & $23.7 \pm 13.9$ & $<0.001$ & ND & ND & ND & & $13.1 \pm 6.2$ & $22.3 \pm 10.6$ & $25.5 \pm 12.9$ & $<0.001$ \\
\hline $\mathrm{T} 2$ & $10.3 \pm 7.6$ & $15.5 \pm 9.4$ & $21.7 \pm 15.6$ & $<0.001$ & $16.5 \pm 9.3$ & $40.7 \pm 17.1$ & $51.8 \pm 20.7$ & $<0.001$ & ND & ND & ND & \\
\hline
\end{tabular}

Data are described as mean \pm SD or numbers.

If Pearson $\chi^{2}$ test for sex and Kruskal-Wallis test for age and serum protein complexes T1 and T2. All statistical tests are two-sided.

ND, no data.

Table 5. Diagnostic performance of serum DRPCs in different patterns

\begin{tabular}{|c|c|c|c|c|c|c|c|}
\hline Patterns & DRPCs & Groups & AUC & $95 \% \mathrm{CI}$ & $\begin{array}{l}\text { Cut-off } \\
\text { value }\end{array}$ & Sensitivity & Specificity \\
\hline \multirow[t]{3}{*}{1} & $\mathrm{~T} 1$ & Controls vs. prediabetes & 0.71 & $0.65-0.77$ & 11.79 & $70.00 \%$ & $63.73 \%$ \\
\hline & & Controls vs. T2DM & 0.77 & $0.73-0.82$ & 42.14 & $87.78 \%$ & $58.38 \%$ \\
\hline & & Prediabetes vs. T2DM & 0.61 & $0.54-0.67$ & 37.35 & $64.71 \%$ & $57.84 \%$ \\
\hline \multirow[t]{3}{*}{1} & $\mathrm{~T} 2$ & Controls vs. prediabetes & 0.70 & $0.64-0.76$ & 7.89 & $68.33 \%$ & $64.71 \%$ \\
\hline & & Controls vs. T2DM & 0.78 & $0.73-0.82$ & 6.73 & $71.11 \%$ & $72.43 \%$ \\
\hline & & Prediabetes vs. T2DM & 0.61 & $0.54-0.68$ & 11.61 & $68.63 \%$ & $50.81 \%$ \\
\hline \multirow[t]{3}{*}{2} & $\mathrm{~T} 2$ & Controls vs. prediabetes & 0.93 & $0.88-0.98$ & 11.52 & $86.00 \%$ & $92.16 \%$ \\
\hline & & Controls vs. T2DM & 0.94 & $0.91-0.97$ & 65.91 & $94.00 \%$ & $80.66 \%$ \\
\hline & & Prediabetes vs. T2DM & 0.59 & $0.50-0.67$ & 55.97 & $86.28 \%$ & $32.04 \%$ \\
\hline \multirow[t]{3}{*}{3} & $\mathrm{~T} 1$ & Controls vs. prediabetes & 0.76 & $0.70-0.81$ & 40.10 & $89.70 \%$ & $53.54 \%$ \\
\hline & & Controls vs. T2DM & 0.82 & $0.78-0.86$ & 8.61 & $89.09 \%$ & $64.29 \%$ \\
\hline & & Prediabetes vs. T2DM & 0.57 & $0.51-0.63$ & 11.75 & $34.29 \%$ & $65.71 \%$ \\
\hline
\end{tabular}

AUC, area under the receiver operating characteristic curve; CI, confidence interval. 
A

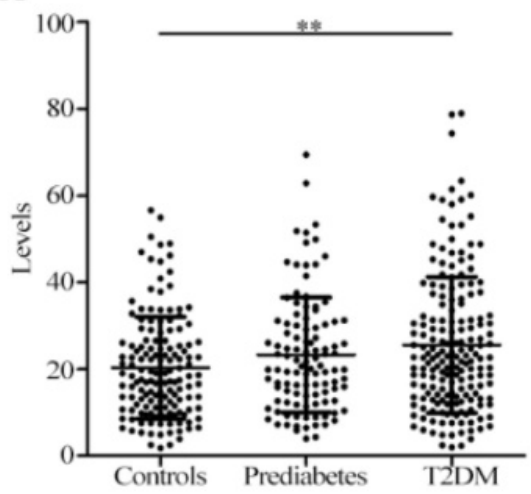

C

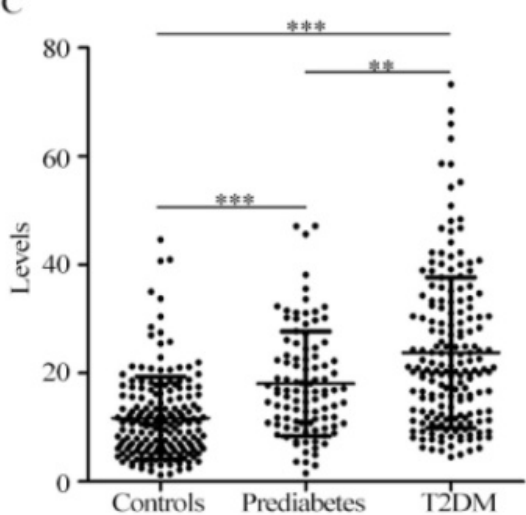

E

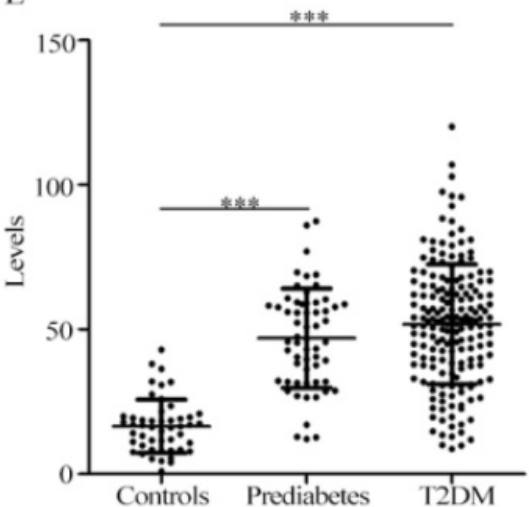

B

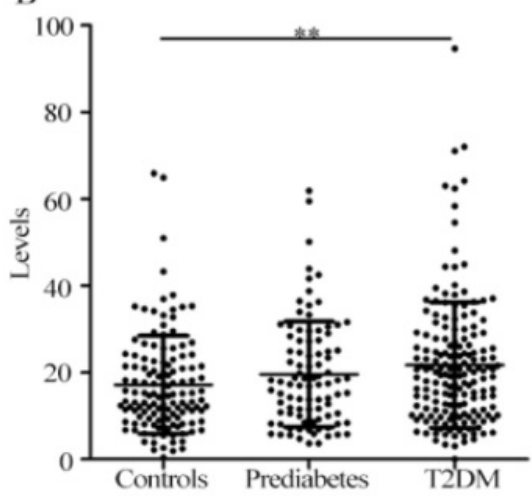

D
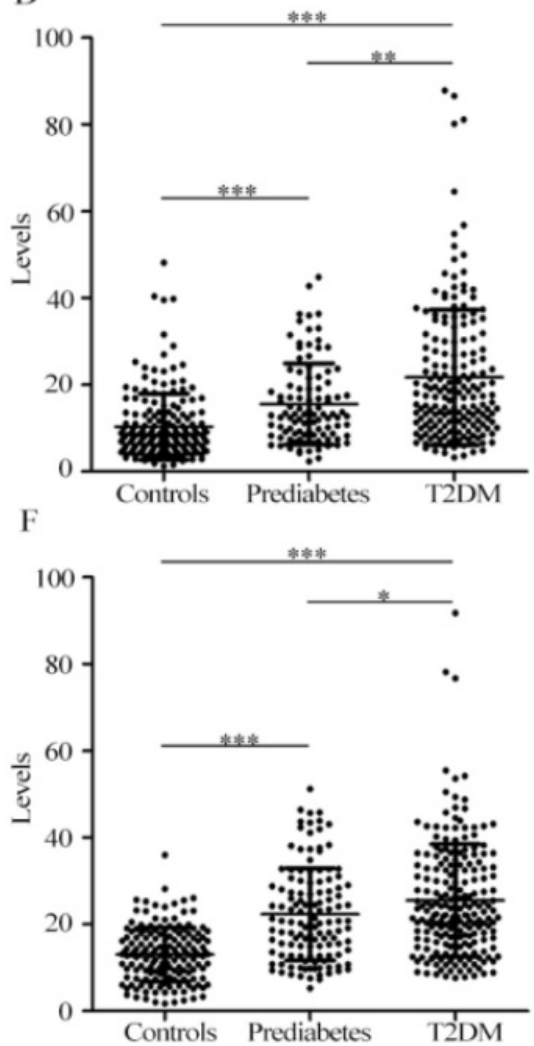

Figure 2. Scatter plots of protein complexes: $\mathrm{a} 3, \mathrm{b4}, \mathrm{T1}$, and $\mathrm{T} 2$ in serum samples from healthy controls, patients with prediabetes, and patients with T2DM. (A) The level of a3; (B) The level of b4; (C) The level of T1 in pattern 1; (D) The level of T2 in pattern 1; (E) The level of T2 in pattern 2; (F) The level of T1 in pattern 3 .***, $^{*}<0.001 ; * *, p<0.01$; $^{*}, p<0.05$.

As shown in Figure 2C-D, for pattern 1, the levels of serum $\mathrm{T} 1$ and $\mathrm{T} 2$ in patients with T2DM remarkably increased compared with patients with prediabetes and controls, and significant increase in the levels of serum $\mathrm{T} 1$ and $\mathrm{T} 2$ in patients with prediabetes were detected compared with controls. For pattern 2, significantly increased level of serum T2 in patients with prediabetes and patients with T2DM was observed compared with controls (Figure 2E), and no difference was detected between prediabetes and T2DM. For pattern 3, the level of serum T1 in patients with T2DM significantly increased relative to patients with prediabetes and controls. Additionally, significant difference was also observed between patients with prediabetes and controls (Figure 2F). ROC curve analysis indicated that serum $\mathrm{T} 2$ in pattern 2 had an excellent diagnostic performance on distinguishing patients with prediabetes and T2DM from controls, with the area under the ROC curve (AUC) of 0.93 and 0.94 , respectively. It is worth noting that T1 and/or T2 from patterns 1,2, or 3 had a similar capability of distinguishing prediabetes from T2DM, with the AUC values from 0.57 to 0.61 . More information of ROC analysis is shown in Table 5. In addition, the components of serum $\mathrm{T} 1$ and $\mathrm{T} 2$ were separated using the sodium dodecyl sulfate-PAGE, followed by identification using mass spectrometry. The components are inter-alpha-trypsin inhibitor 
heavy chain $\mathrm{H} 1$ and $\mathrm{H} 2$, complement $\mathrm{C} 3 \beta$-subunit, haptoglobin $\beta$-subunit, and apolipoprotein A-I.

\section{Discussion}

In this study, serum protein complexes of interest were isolated using the optimized native-PAGE approach. According to the linear dynamic range of the loading serum volume, it was found that $2 \mu \mathrm{L}$ of serum is an appropriate loading volume for electrophoresis separation. The RSDs of intraday and interday precision were less than $20 \%$, indicating that the method is acceptable for complex biological sample analysis. It should be noted that serum TRPC is an internal reference to quantify serum protein complexes of interest.

The main components of serum IIRPCs are immunoglobulin G1, immunoglobulin A1, haptoglobin, complement $\mathrm{C} 3$, complement $\mathrm{C} 4 \mathrm{~A}$, complement $\mathrm{C}$, complement $\mathrm{C}$, complement factor $\mathrm{H}$, transferrin, and apolipoprotein A-I, which are immunity-related proteins, inflammation-related proteins, and complement-related proteins. Previous studies have indicated that serum IIRPCs are closely associated with cancers, chronic diseases, and the development of lung cancer $[11,17]$, suggesting that they may be excellent indicators of humoral immune responses and inflammatory responses. In this study, serum IIRPCs in patients with T2DM also increased compared with controls, but no difference in between controls and patients with prediabetes and in between prediabetes and T2DM was detected, suggesting that serum IIRPCs may be closely associated with T2DM.

The main components of serum DRPCs are complement C3- $\beta$ subunit, inter-alpha-trypsin inhibitor heavy chain $\mathrm{H} 1$ and $\mathrm{H} 2$, haptoglobin $\beta$ subunit, and apolipoprotein A-I. Some of them are inflammation-related proteins and complement-related proteins. All serum samples from 1446 participants were classified into four patterns based on the position distributions of serum DRPCs (T1 andT2) in their native-PAGE gels. The levels of serum DRPCs had a positive correlation with blood glucose levels in an order of patients with T2DM> patients with prediabetes>healthy controls. More importantly, significant increase in the levels of serum DRPCs may be closely associated with the development of T2DM. Previous studies have shown that circulating inflammatory factors and innate immune cells-related activated factors elevated in patients with T2DM[4, 20-22], including a-1 acid glycoprotein, sialic acid, IL-6, and urinary albumin, especially for CRP, which plays an important role in diabetes mellitus and diabetic complications[23-25]. Complement C3, a central component of complement system, is closely associated with inflammatory response, and the incorporation of $\mathrm{C} 3$ into clot from diabetic fibrinogen is enhanced in patients with type 1 diabetes [26]. A large cohort study has indicated that complement $\mathrm{C} 3$ is a risk factor to develop diabetes [27]. Inter-alpha-trypsin inhibitor (ITI or IaI) is composed of one light chain and six heavy chains (H1, $\mathrm{H} 2, \mathrm{H} 3, \mathrm{H} 4, \mathrm{H} 5$, and H5L) [28]. In this study, H1 and $\mathrm{H} 2$ were detected. IaI is involved in inflammation and complement activation [29-31]. Haptoglobin is one of the most important acute phase proteins, the genotype of which might play a very important role in diabetes and diabetic complications [32-36]. Apolipoprotein A-I, a principal protein in high-density lipoprotein (HDL), has an anti-inflammatory function [37]. In addition, apolipoprotein A-I can interact with haptoglobin to form protein complex [38, 39]. All above-mentioned studies indicate that serum DRPCs may be associated with inflammatory responses and may play a crucial role in the development of T2DM.

There were some meaningful findings and limitations in this study. First, we used a simple and economic gel separation method to obtain diabetes-related protein complexes in serum. Second, serum IIRPCs are not only associated with cancers, chronic diseases, and the development of lung cancer, but also closely associated with T2DM. Third, all serum samples could be classified into four types based on the patterns of serum DRPCs. Significantly increased levels of serum DRPCs were correlated with prediabetes and T2DM, indicating that serum DRPCs may be unique, personalized biomarkers for T2DM. In addition, it should be noted that the mechanisms need to be further confirmed, and that the factors, such as height, weight, waist circumference, hip circumference, and blood pressure should be included in the future study.

\section{Conclusions}

The optimized native-PAGE approach combined with mass spectrometry was used to separate and identify serum protein complexes from controls, patients with prediabetes, and patients with T2DM. All participants could be classified into four and seven groups based on serum DRPCs and IIRPCs, respectively. The levels of serum DRPCs in patients with prediabetes and T2DM increased compared with controls. Our findings suggest that increased levels of serum IIRPCs and DRPCs were associated with T2DM.

\section{Abbreviations}

IIRPCs: immunoinflammation-related protein complexes; DRPCs: diabetes-related protein complexes; TRPC: transferrin-related protein 
complex; T2DM: type 2 diabetes mellitus; FPG: fasting plasma glucose; QC: quality control; CRP: C reactive protein; PAGE: polyacrylamide gel electrophoresis; ROC: receiver operating characteristic.

\section{Acknowledgement}

This study was funded by the Capital Medical Research Development Found of China (Grant No. 2016-1-2031).

\section{Competing Interests}

The authors have declared that no competing interest exists.

\section{References}

1. Stumvoll M, Goldstein BJ, van Haeften TW Type 2 diabetes: principles of pathogenesis and therapy. Lancet 2005,365: 1333-1346.

2. Stumvoll M, Goldstein BJ, van Haeften TW Pathogenesis of type 2 diabetes. Endocr Res 2007,32: 19-37.

3. Pickup JC Inflammation and activated innate immunity in the pathogenesis of type 2 diabetes. Diabetes Care 2004,27: 813-823.

4. Donath MY, Shoelson SE Type 2 diabetes as an inflammatory disease. Nat Rev Immunol 2011,11: 98-107.

5. Akash MS, Rehman $\mathrm{K}$, Chen $\mathrm{S}$ Role of inflammatory mechanisms in pathogenesis of type 2 diabetes mellitus. J Cell Biochem 2013,114: 525-531.

6. Dehghan A, Kardys I, de Maat MP, Uitterlinden AG, Sijbrands EJ, Bootsma AH, Stijnen T, Hofman A, Schram MT, Witteman JC Genetic variation, C-reactive protein levels, and incidence of diabetes. Diabetes 2007,56: 872-878.

7. Pickup JC, Mattock MB, Chusney GD, Burt D NIDDM as a disease of the innate immune system: association of acute-phase reactants and interleukin-6 with metabolic syndrome X. Diabetologia 1997,40: 1286-1292.

8. Herder C, Brunner EJ, Rathmann W, Strassburger K, Tabak AG, Schloot NC, Witte DR Elevated levels of the anti-inflammatory interleukin-1 receptor antagonist precede the onset of type 2 diabetes: the Whitehall II study. Diabetes Care 2009,32: 421-423.

9. Hedstrom J, Sainio V, Kemppainen E, Haapiainen R, Kivilaakso E, Schroder T, Leinonen J, Stenman U-H Serum complex of trypsin 2 and (alpha)(sub 1) antitrypsin as diagnostic and prognostic marker of acute pancreatitis: clinical study in consecutive patients. BMJ 1996,313: 333-337.

10. Holzinger D, Frosch M, Kastrup A, Prince FHM, Otten MH, Van Suijlekom-Smit LWA, Cate Rt, Hoppenreijs EPAH, Hansmann S, Moncrieffe H, Ursu S, Wedderburn LR, Roth J, Foell D, Wittkowski H The Toll-like receptor 4 agonist MRP8/14 protein complex is a sensitive indicator for disease activity and predicts relapses in systemic-onset juvenile idiopathic arthritis. Ann Rheu Dis 2012,71: 974-980.

11. Wang Y, Song G, Wang Y, Qiu L, Qin X, Liu H, Li F, Wang X, Li F, Guo S, Zhang $Y, \mathrm{Li} Z$ Elevated serum levels of circulating immunoinflammation-related protein complexes are associated with cancer. J Proteome Res 2014,13: 710-719.

12. Teitel J, Bauer K, Lau H, Rosenberg R Studies of the prothrombin activation pathway utilizing radioimmunoassays for the F2/F1 + 2 fragment and thrombin--antithrombin complex. Blood 1982,59: 1086-1097.

13. Lempinen M, Stenman UH, Halttunen J, Puolakkainen P, Haapiainen R, Kemppainen E Early sequential changes in serum markers of acute pancreatitis induced by endoscopic retrograde cholangiopancreatography. Pancreatology 2005,5: 157-164.

14. Kim J, Bhattacharjee R, Snow AB, Capdevila OS, Kheirandish-Gozal L, Gozal D Myeloid-related protein 8/14 levels in children with obstructive sleep apnoea. Eur Respir J 2010,35: 843-850.

15. Schagger $H$, von Jagow $G$ Blue native electrophoresis for isolation of membrane protein complexes in enzymatically active form. Anal Biochem 1991,199: 223-231.

16. Wittig I, Karas M, Schagger H High resolution clear native electrophoresis for in-gel functional assays and fluorescence studies of membrane protein complexes. Mol Cell Proteomics 2007,6: 1215-1225.

17. Song G, Liu Y, Wang Y, Ren G, Guo S, Ren J, Zhang L, Li Z Personalized biomarkers to monitor disease progression in advanced non-small-cell lung cancer patients treated with icotinib. Clin Chim Acta 2015,440: 44-48.

18. Santos CR, Schulze A Lipid metabolism in cancer. Febs Journal 2012,279: 2610-2623.

19. Chen G, Luo Y, Wang X, Zhao Z, Liu H, Zhang H, Li Z A relatively simple and economical protocol for proteomic analyses of human $20 \mathrm{~S}$ proteasome: Compatible with both scaled-up and scaled-down purifications. Electrophoresis 2009,30: 2422-2430.

20. Pickup JC, Crook MA Is Type II diabetes mellitus a disease of the innate immune system? Diabetologia 1998,41: 1241-1248.
21. Lontchi-Yimagou E, Sobngwi E, Matsha T, Kengne A Diabetes Mellitus and Inflammation. Current Diabetes Reports 2013,13: 435-444.

22. Kolb H, Mandrup-Poulsen $\mathrm{T}$ An immune origin of type 2 diabetes? Diabetologia 2005,48: 1038-1050.

23. Pradhan AD, Manson JE, Rifai N, Buring JE, Ridker PM C-reactive protein, interleukin 6, and risk of developing type 2 diabetes mellitus. JAMA 2001,286: 327-334.

24. Linnemann B, Voigt W, Nobel W, Janka HU C-Reactive Protein is a Strong Independent Predictor of Death in Type 2 Diabetes: Association with Multiple Facets of the Metabolic Syndrome. Exp Clin Endocrinol Diabetes 2006,114: 127-134.

25. Freeman DJ, Norrie J, Caslake MJ, Gaw A, Ford I, Lowe GDO, O'Reilly DSJ, Packard CJ, Sattar N C-Reactive Protein Is an Independent Predictor of Risk for the Development of Diabetes in the West of Scotland Coronary Prevention Study. Diabetes 2002,51: 1596-1600.

26. Hess K, Alzahrani SH, Mathai M, Schroeder V, Carter AM, Howell G, Koko T, Strachan MWJ, Price JF, Smith KA, Grant PJ, Ajjan RA A novel mechanism for hypofibrinolysis in diabetes: the role of complement C3. Diabetologia 2012,55: 1103-1113.

27. Engström G, Hedblad B, Eriksson K-F, Janzon L, Lindgärde F Complement C3 Is a Risk Factor for the Development of Diabetes: A Population-Based Cohort Study. Diabetes 2005,54: 570-575.

28. Zhuo L, Kimata K Structure and Function of Inter-a-Trypsin Inhibitor Heavy Chains. Connective Tissue Research 2008,49: 311-320.

29. Garantziotis S, Hollingsworth JW, Ghanayem RB, Timberlake S, Zhuo L, Kimata K, Schwartz DA Inter-alpha-trypsin inhibitor attenuates complement activation and complement-induced lung injury. J Immunol 2007,179: 4187-4192.

30. Daveau M, Rouet P, Scotte M, Faye L, Hiron M, Lebreton JP, Salier JP Human inter-alpha-inhibitor family in inflammation: simultaneous synthesis of positive and negative acute-phase proteins. Biochem J 1993,292 ( Pt 2): 485-492.

31. Choi-Miura NH, Takahashi K, Yoda M, Saito K, Hori M, Ozaki H, Mazda T, Tomita M The novel acute phase protein, IHRP, inhibits actin polymerization and phagocytosis of polymorphonuclear cells. Inflammation Research 2000,49: $305-310$.

32. Xiaohong Shi LS, Li Wang, Feng Jin, Junfeng Sun, Xiaoquan Zhu, Lei Tang, Yanchun Qu, and Ze Yang Haptoglobin 2-2 Genotype Is Associated with Increased Risk of Type 2 Diabetes Mellitus in Northern Chinese. Genetic Testing and Molecular Biomarkers 2012,16: 563-568.

33. Mustafa S, Vukovich T, Prikoszovich T, Winzer C, Schneider B, Esterbauer H, Wagner O, Kautzky-Willer A Haptoglobin phenotype and gestational diabetes. Diabetes Care 2004,27: 2103-2107.

34. Kruger AJ, Yang C, Tam SW, Hinerfeld D, Evans JE, Green KM, Leszyk J, Yang K, Guberski DL, Mordes JP, Greiner DL, Rossini AA, Bortell R Haptoglobin as an early serum biomarker of virus-induced autoimmune type 1 diabetes in biobreeding diabetes resistant and LEW1.WR1 rats. Experimental Biology and Medicine 2010,235: 1328-1337.

35. Costacou T, Levy AP Haptoglobin genotype and its role in diabetic cardiovascular disease. J Cardiovasc Transl Res 2012,5: 423-435.

36. Costacou T, Ferrell RE, Ellis D, Orchard TJ Haptoglobin genotype and renal function decline in type 1 diabetes. Diabetes 2009,58: 2904-2909.

37. Murphy AJ, Hoang A, Aprico A, Sviridov D, Chin-Dusting J Anti-Inflammatory Functions of Apolipoprotein A-I and High-Density Lipoprotein Are Preserved in Trimeric Apolipoprotein A-I. Journal of Pharmacology and Experimental Therapeutics 2013,344: 41-49.

38. Spagnuolo MS, Cigliano L, Abrescia P The binding of haptoglobin to apolipoprotein AI: influence of hemoglobin and concanavalin A. Biol Chem 2003,384: 1593-1596.

39. Salvatore A, Cigliano L, Bucci EM, Corpillo D, Velasco S, Carlucci A, Pedone C, Abrescia P Haptoglobin Binding to Apolipoprotein A-I Prevents Damage from Hydroxyl Radicals on Its Stimulatory Activity of the Enzyme Lecithin-Cholesterol Acyl-Transferaset. Biochemistry 2007,46: 11158-11168. 